\title{
Assessment of Aortic Elasticity and the Doppler Tissue Echocardiography in Thalassemia Major Children
}

\author{
Noor Mohammad Noori ${ }^{1} \quad$ Alireza Teimouri ${ }^{10} \quad$ Kambiz Keshavarz ${ }^{2}$ Malihe Moradi ${ }^{3}$ \\ ${ }^{1}$ Children and Adolescent Health Research Center, Resistant \\ Tuberculosis Institute, School of Medicine, Zahedan University of \\ Medical Sciences, Zahedan, Iran \\ ${ }^{2}$ School of Medicine, University of Medical Sciences, Yasuj, Iran

\begin{abstract}
Address for correspondence Alireza Teimouri M.Phil, PhD, Children and Adolescent Health Research Center, Resistant Tuberculosis Institute, School of Medicine, Zahedan University of Medical Sciences,
\end{abstract} \\ Zahedan, Iran (e-mail: alirezateimouri260@gmail.com).
}

${ }^{3}$ School of Medicine, University of Medical Science, Zahedan, Iran

J Child Sci 2020;10:e63-e73.

\begin{abstract}
Keywords

- aortic elasticity

- Doppler tissue echocardiography

- thalassemia

- children

Cardiovascular diseases are the most common illness that needs special medical care in thalassemia particularly in children and adolescents. We aimed to compare aortic stiffness in thalassemia major and healthy children. The study included 65 asymptomatic thalassemia major 6 to 19-year-old children without known history of heart disease and 65 age- and sex-matched healthy controls. Arterial stiffness indices determined using two-dimensional (2D) and Doppler echocardiography. Data were analyzed by SPSS 20.0 with 0.05 as significant error. From the study, results showed that systolic $(p=0.009)$ and diastolic $(p<0.001)$ blood pressures were higher in controls. Left ventricular mass index (LVMI) was higher in patients $(p<0.001)$. Aortic stiffness index $(p<0.001)$, pulse pressure $(p<0.001)$, and pressure strain elastic modulus $(p<0.001)$ were higher in patients, while aortic strain $(p<0.002)$ and aortic distensibility $(p<0.001)$ were lower significantly. Aortic stiffness index was correlated with diastole aorta $(p=0.005)$, systole aorta $(p<0.001)$, and LVMI $(p<0.001)$. Strain was correlated with diastole aorta $(p<0.001)$. Pulse pressure was correlated with systolic blood pressure $(p<0.001)$, diastolic blood pressure $(p=0.002)$ significantly. Aortic distensibility was correlated with systolic blood pressure $(p=0.039)$ and diastole aorta $(p<0.001)$ significantly. The pressure strain elastic modulus was correlated only with diastole aorta $(p=0.029)$. Concluded, aortic stiffness index, pulse pressure, and pressure strain elastic modulus were higher in thalassemia children, while aortic strain and aortic distensibility were lower. This increase may result in reduction of mechanical efficiency of the heart. Therefore, assessment of aortic elastic properties as nontraditional cardiovascular risk factors may contribute to the identification of cardiovascular risks in children with thalassemia
\end{abstract}

\section{Introduction}

Cardiovascular disease (CVD) is a class of diseases that involve the heart or blood vessels which needs restorative consideration exceptionally in children. One of the most significant noninvasive strategies is assessing aortic elastic parameters to recognize future cardiovascular events. ${ }^{1}$ The

received

March 17, 2020

accepted

May 8, 2020
DOI https://doi.org/

10.1055/s-0040-1713595. ISSN 2474-5871. parameters of aortic elastic regular are the after effect of incorporating cardiovascular hazard factors on the blood vessel divider over an extensive stretch of time. Estimating these parameters may open a window of opportunity to stop the event of cardiovascular infection. ${ }^{2}$ The parameters are the consequence of regular maturing and natural aging that might be affected by numerous components of hereditary
Copyright (c) 2020 Georg Thieme Verlag License terms KG Stuttgart · New York 
inclination and cardiovascular hazard factors such as blood vessel hypertension, hypercholesterolemia, diabetes mellitus, smoking, and physical movement. ${ }^{3}$ They are early signs of structural and functional changes of the vessel wall and an independent predictor of cardiovascular disorders that arise as a consequence of arteriosclerosis. ${ }^{2}$ Many studies have been conducted about the aortic elastic changes due to various diseases. ${ }^{4-11}$ Bayar et $\mathrm{al}^{4}$ found changes in arterial stiffness parameters in patients with celiac diseases compared with the healthy when Ülger et $\mathrm{a}^{5}$ did not find any changes in asthma patients. In this regard, Bektaş et al ${ }^{6}$ found a significant change in asthmatic patients compared with posttreatment asthmatic patients. Prenner and Chirinos, ${ }^{7}$ Zapolski et al, ${ }^{8}$ and Sahin et $\mathrm{al}^{9}$ found an increase of arterial stiffness parameters in diabetes mellitus, end stage renal and thalassemia major (TM) diseases compared with healthy in the order given. In addition, considering TM patients, Sherief et $\mathrm{al}^{10}$ used the method of carotid artery intima media thickness and found a significant increase, while Cusmà Piccione et al $^{11}$ did not find. But the arterial stiffness was increased significantly. Physiopathology of vasculopathy in patients with TM cannot be explained by iron-related oxidative injury alone, as aortic elastic or similar disorder does not always accompany to hemochromatosis. ${ }^{9}$ In patients with $\mathrm{TM}$, structural changes in available mechanisms result in altered elasticity of vessels in subsequent period, thus, predispose to arterial dysfunction. ${ }^{12}$ Recently, arterial elasticity parameters are assessed by relatively simple, noninvasive methods to assess vascular involvement in patient with TM especially. Increased aortic stiffness or decreased distensibility is applied as a marker for diffuse atherosclerotic involvement in vascular system. ${ }^{9}$ Moreover, in some studies suggested, arterial stiffness can be used as a marker for early cardiovascular and vascular involvement in asymptomatic TM patients without significant iron load ${ }^{13}$ and without any correlations with ferritin. ${ }^{14}$ To date, no studies have yet been performed on aortic stiffness parameters on patients with TM in this region. Therefore, the present study aimed to assess the aortic strain; stiffness and elasticity in TM patients and compare with healthy children.

\section{Materials and Methods}

\section{Study Design}

This case-control study was performed on 130 participants aged 6 to 19 years consisted of 65 healthy children as controls and 65 thalassemia children as case group in pediatric cardiac center in collaboration with center for specific diseases at Ali Asghar Hospital of Zahedan in Sistan and Baluchistan provinces, Iran, from 2018 September to 2019 August. Thalassemia children collected from those thalassemia patients who were asymptomatic and those patients who had regular transfusions of hemoglobin higher than $10 \mathrm{~g} / \mathrm{dL}$ and 48 to 72 hours after packed red blood cell transfusion were entered into the study. From selected patients, two had ejection fraction lower than $60 \%$ in which both were girls with 18 years that had 55 and $59 \%$. Control children collected from those healthy children that referred to the clinics for routine check-up.

\section{Criteria}

Exclusion criteria in both groups of participants were valvular heart disease, rhythm, and structural abnormality, active infection, systemic inflammatory diseases, and renal insufficiency.

\section{Echocardiography Measurements}

Major proceedings on patients were checking medical history, physical examination, chest X-ray, and echocardiography which was performed by one pediatric cardiologist. Echocardiography was performed on participants by the same pediatric cardiologist using the My laboratory 60 with transducer 3, 8 (made in Italy). To achieve high precision in echocardiography findings, measurement was repeated for three cycles and the average was considered. Echocardiogram was performed on participants without them holding their breath.

Echocardiography findings by M-mode (a diagnostic ultrasound presentation of the temporal changes in echoes in which the depth of echo-producing interfaces is displayed with two axes of time and motion ) were diastolic diameter of the aorta (Aod), systolic diameter of the aorta (Aos), left ventricular end diastolic dimension (LVDD), posterior wall dimension (PWD) in diastole, interventricular septal dimension in diastole (IVSD), interventricular septal dimension in systole (IVSS), relative wall thickness (RWT) that defined as twice PWT divided by the LV diastolic diameter, ejection fraction(EF), fractional shortening(FS), LV mass (LVM), and LVM index (LVMI) were measured using conventional echocardiography of the left side and estimated from three cardiac cycles. LVMI was calculated by the following formula: LVM $(\mathrm{g})=0.8(1.04$ $\left[\right.$ LVDD + PWD + IVSD ${ }^{3}-$ LVDD $\left.\left.^{3}\right]+0.6\right)$, and LVMI ( $/$ $\left.\mathrm{m}^{2}\right)=\mathrm{LVM} / 2.7\left(\mathrm{~g} / \mathrm{m}^{2}\right)$. All the parameters in the above formula were measured in the M-mode view and in diastole and were utilized for LVM evaluation. ${ }^{15}$ After routine echocardiographic investigation, ascending aorta were obtained from $3 \mathrm{~cm}$ above the aortic valve by the M-mode. Aortic diameters were calculated as the distance between the anterior and posterior wall inner edges of the aorta at systole and diastole. Aos was recorded when the aortic wall was fully open. Aod was recorded simultaneously when the QRS peak was seen on electrocardiographic (ECG) recordings. Measurements were taken during three consecutive pulses and the mean was calculated. The Doppler tissue echocardiography (DTE) is another method that was performed from the apical fourchamber view and a 3-mm pulsed Doppler sample volume was placed at the level of lateral mitral annulus. Myocardial velocity profiles of the lateral tricuspid annulus and lateral mitral annulus were obtained by placing the sample volume at the junction of the tricuspid annulus and the right ventricle (RV) free wall and at the junction of the mitral annulus and LV posterior wall, respectively. With this modality, the recorded values were the early $\left(E^{\prime}\right)$ and late $\left(A^{\prime}\right)$ diastolic mitral and tricuspid annular velocities, and the ratio of $\mathrm{E}^{\prime} / \mathrm{A}^{\prime}$. Left and right $S^{\prime}$ : systolic myocardial velocity above the baseline in mitral and tricuspid. Left and right $E^{\prime}$ : early diastolic myocardial relaxation velocity below the baseline in mitral and tricuspid. Left and right $A^{\prime}$ : myocardial velocity associated with atrial contraction in mitral and tricuspid. ${ }^{16}$ 


\section{Blood Pressure Measurement}

Blood pressure (BP) levels were measured from the brachial artery at the level of the heart with a sphygmomanometer after resting for at least 5 minutes in the supine position. Three measurements, at least 2-minute apart, were performed, and the average of the closest two readings was recorded. A pressure drop rate of approximately $2 \mathrm{~mm} \mathrm{Hg} / \mathrm{s}$ was applied, and Korotkoff's phases I and V were used for systolic and diastolic BP (SBP and DBP, respectively) levels, respectively. All BP measurements were made by a cardiologist. Pulse pressure (PP) was calculated as systolic minus diastolic BP.

\section{Aortic Elasticity Parameters}

The systolic and diastolic ascending aortic diameters were recorded in M-mode under echocardiographic and electrocardiographic guidance approximately $3 \mathrm{~cm}$ above the aortic valve from parasternal long-axis views. The systolic aortic diameter was measured at the time of maximum anterior motion of the aorta, while the diastolic diameter was measured at the start of the QRS complex in electrocardiography (-Fig. 1). The following formulas were used to assess the aortic elasticity of the aorta. ${ }^{4}$

Aortic strain (\%) $=($ aortic SD [systolic diameter] - aortic DD [diastolic diameter] $) \times 100 /$ aortic DD

Aortic stiffness $\boldsymbol{\beta}$ index = natural logarithm (SBP [BP]/ DBP $) /([$ aortic SD - aortic DD]/aortic DD)

Aortic distensibility $\left(\mathrm{cm}^{2} \times\right.$ dyne-1.10-6) $=2 \times([$ aortic $\mathrm{SD}$ - aortic DD]/aortic DD)/(SBP - DBP)

Pressure strain elastic modulus $=(S B P-D B P) /([$ aortic $\mathrm{SD}$ - aortic DD]/aortic DD)

\section{Anthropomorphic Measurements}

The participants' height and weight were measured by an experienced expert using standard equipment. Then, body mass index (BMI) was calculated according to the 2,000 sexspecific BMI-for-age growth charts of the Centers for Disease Control and Prevention. Participants' height was measured in the standing position with a balance using a scaled ruler and weight was calculated using a RAhpouyan Salamat Azma (RASA) scale factor with an error of $100 \mathrm{~g}$ (made in Iran). Then BMI was calculated as weight $(\mathrm{kg}) /$ height $\left(\mathrm{m}^{2}\right)$.

\section{Ethical Approval}

Consent form was obtained from the participants or their guardians after the study approval. The study was approved as a project proposed to the Children and Adolescent Health Research Center by the Ethics Committee of Zahedan University of Medical Sciences, Zahedan, Iran (ID number: 6798).

\section{Statistical Analysis}

Data were analyzed by using SPSS for Windows version 20.0 (SPSS Inc.; Chicago, Illinois, United States). KolmogorovSmirnov test was used to assess distribution of continuous variables where homogeneity was tested. Student's $t$-test was used to compare mean values of quantitative variables with normal distribution while Mann-Whitney $U$-test was used to compare quantitative variables with skewed distribution. In correlation analyses, Pearson's test was used for parametric variables while Spearmen's test was used for nonparametric variables. $p$-Value of $<0.05$ was considered as statistically significant.

\section{Results}

The study aimed to assess the aortic stiffness parameters in TM children comparing with controls. A total of 130 participants were entered into the study with 65 in each group. Sex distribution was 42.3 and $57.7 \%$ in terms of females and males, respectively. In patients, 28 (43.1\%) were females and this pattern was 27 (41.5\%) for the controls. - Table 1 showed the data distribution in participants and only patients. In the case of participants, Aod, Aos, LVDD, LVDS, EF, FS, and BMI were distributed normally $(p>0.05)$. The remaining variables had free distribution. In the case of only patients, the results revealed that height, Aod, Aos. IVSD, LVDD, EF, FS, Left E', BMI, LVMI, Left $E^{\prime} / A^{\prime}$, and right $E^{\prime} / A^{\prime}$ were normal $(p>0.05)$.

- Table 2 showed the quantities variables comparative in TM and controls based on nonparametric Mann-Whitney $U$ test. The tables showed that the participant in TM and controls were similar in age $(p=0.0 .05)$. Weight $(p<0.001))$ and height $(p=0.001)$ of the patients were lower than controls. Systolic $(p=0.009)$ and diastolic $(p<0.001)$ blood pressures were higher in controls compared with patients, while conventional echocardiography parameters, such as IVSD, PWD, IVSS, and

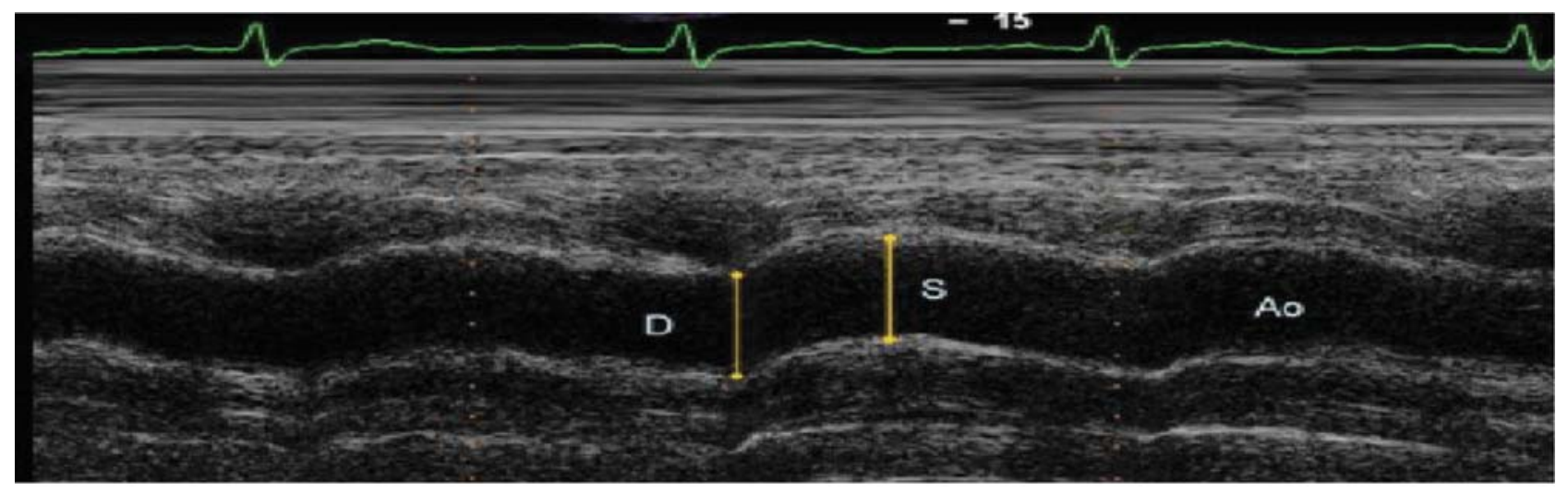

Fig. 1 Measurements of systolic (S) and diastolic (D) diameters of the ascending aorta are shown on the M-mode tracing obtained at a level $3 \mathrm{~cm}$ above the aortic valve. 
Table 1 Normality test for quantities variables in participants and TM patients

\begin{tabular}{|c|c|c|c|c|c|c|c|c|}
\hline \multirow[t]{2}{*}{ Variables } & \multicolumn{4}{|c|}{ All participants } & \multicolumn{4}{|c|}{ TM patients } \\
\hline & Mean & SD & KS & $p$ & Mean & SD & KS & $p$ \\
\hline Age (y) & 13.7 & 3.65 & 0.14 & $<0.001$ & 13.98 & 3.84 & 0.15 & 0.001 \\
\hline Weight $(\mathrm{kg})$ & 41.49 & 13.88 & 0.08 & 0.037 & 36.23 & 11.71 & 0.11 & 0.039 \\
\hline Height $(\mathrm{cm})$ & 145.22 & 16.91 & 0.08 & 0.04 & 139.98 & 16.54 & 0.11 & 0.052 \\
\hline SBP $(\mathrm{mm} \mathrm{Hg})$ & 105.38 & 6.81 & 0.18 & $<0.001$ & 103.46 & 5.99 & 0.16 & $<0.001$ \\
\hline DBP $(\mathrm{mm} \mathrm{Hg})$ & 68.07 & 6.97 & 0.17 & $<0.001$ & 63.52 & 5.34 & 0.21 & $<0.001$ \\
\hline Aod $(\mathrm{cm})$ & 2.00 & 0.28 & 0.06 & 0.2 & 1.97 & 0.3 & 0.08 & 0.2 \\
\hline Aos $(\mathrm{cm})$ & 2.42 & 0.3 & 0.05 & 0.2 & 2.35 & 0.31 & 0.07 & 0.2 \\
\hline IVSD (cm) & 0.76 & 0.18 & 0.09 & 0.007 & 0.86 & 0.17 & 0.07 & 0.2 \\
\hline $\operatorname{LVDD}(\mathrm{cm})$ & 4.01 & 0.51 & 0.05 & 0.2 & 4.26 & 0.44 & 0.08 & 0.2 \\
\hline PWD $(\mathrm{cm})$ & 0.39 & 0.07 & 0.1 & 0.002 & 0.42 & 0.07 & 0.18 & $<0.001$ \\
\hline IVSS (cm) & 0.93 & 0.2 & 0.15 & $<0.001$ & 1.01 & 0.2 & 0.17 & $<0.001$ \\
\hline LVDS (cm) & 2.23 & 0.38 & 0.07 & 0.094 & 2.42 & 0.36 & 0.14 & 0.005 \\
\hline PWS (cm) & 0.39 & 0.07 & 0.11 & 0.001 & 0.42 & 0.07 & 0.18 & $<0.001$ \\
\hline $\mathrm{EF}(\%)$ & 0.76 & 0.06 & 0.07 & 0.2 & 0.74 & 0.06 & 0.1 & 0.08 \\
\hline FS (\%) & 0.43 & 0.06 & 0.07 & 0.2 & 0.41 & 0.05 & 0.08 & 0.2 \\
\hline Left $\mathrm{S}^{\prime}(\mathrm{m} / \mathrm{s})$ & 0.09 & 0.01 & 0.19 & $<0.001$ & 0.08 & 0.01 & 0.18 & $<0.001$ \\
\hline Left $A^{\prime}(\mathrm{m} / \mathrm{s})$ & 0.16 & 0.03 & 0.1 & 0.005 & 0.17 & 0.03 & 0.1 & 0.184 \\
\hline Left $E^{\prime}(\mathrm{m} / \mathrm{s})$ & 0.07 & 0.02 & 0.18 & $<0.001$ & 0.06 & 0.02 & 0.18 & $<0.001$ \\
\hline Right $\mathrm{S}^{\prime}(\mathrm{m} / \mathrm{s})$ & 0.10 & 0.07 & 0.33 & $<0.001$ & 0.12 & 0.1 & 0.41 & $<0.001$ \\
\hline Right $A^{\prime}(\mathrm{m} / \mathrm{s})$ & 0.15 & 0.02 & 0.12 & $<0.001$ & 0.15 & 0.03 & 0.13 & 0.013 \\
\hline Right E' $(\mathrm{m} / \mathrm{s})$ & 0.08 & 0.02 & 0.17 & $<0.001$ & 0.08 & 0.02 & 0.15 & 0.001 \\
\hline $\mathrm{AS}^{\prime}$ & 5.28 & 0.39 & 0.13 & $<0.001$ & 5.47 & 0.43 & 0.12 & 0.022 \\
\hline Strain (\%) & 21.21 & 6.87 & 0.09 & 0.008 & 19.82 & 8.6 & 0.13 & 0.011 \\
\hline $\mathrm{PP}(\mathrm{mm} \mathrm{Hg})$ & 37.32 & 6.15 & 0.22 & $<0.001$ & 39.94 & 5.36 & 0.27 & $<0.001$ \\
\hline $\mathrm{AD}\left(\mathrm{cm}^{2} \times\right.$ dyne $\left.^{-1} \times 10^{-6}\right)$ & 1.18 & 0.44 & 0.1 & 0.006 & 1.01 & 0.43 & 0.16 & $<0.001$ \\
\hline PSEM (kPa) & 2.03 & 1.14 & 0.24 & $<0.001$ & 2.46 & 1.44 & 0.25 & $<0.001$ \\
\hline BMI $\left(\mathrm{kg} / \mathrm{m}^{2}\right)$ & 19.02 & 2.8 & 0.05 & 0.2 & 17.93 & 2.66 & 0.08 & 0.2 \\
\hline RWT & 0.19 & 0.03 & 0.09 & 0.007 & 0.2 & 0.03 & 0.14 & 0.003 \\
\hline $\operatorname{LVMI}\left(\mathrm{g} / \mathrm{m}^{2}\right)$ & 38.34 & 16.07 & 0.11 & $<0.001$ & 48.01 & 15.61 & 0.11 & 0.061 \\
\hline Left $E^{\prime} / A^{\prime}$ & 2.49 & 0.69 & 0.08 & 0.044 & 2.72 & 0.68 & 0.08 & 0.2 \\
\hline Right $E^{\prime} / A^{\prime}$ & 1.99 & 0.39 & 0.08 & 0.035 & 1.93 & 0.47 & 0.09 & 0.2 \\
\hline
\end{tabular}

Abbreviations: A', late diastolic myocardial velocity; AD, aortic destensibility; Aod, aortic diameter in diastole; Aos, aortic diameter in Systole; ASI, aortic stiffness index; BMI, body mass index; DBP, diastolic blood pressure; $\mathrm{E}^{\prime}$, early diastolic myocardial relaxation velocity; EF, ejection fraction; FS, fractional shortening; IVSD, interventricular septal dimension in Diastole; IVSS, interventricular septal dimension in systole; KS, KolmogorovSmirnov; LVDD, left ventricular end diastolic dimension; LVDS, left ventricular end systolic dimension; LVMI, left ventricular mass index; PP, pulse pressure; PSEM, pressure strain elastic modulus; PWD, posterior wall dimension in diastole; PWS, posterior wall dimension in systole; RWT, relative wall thickness; S', systolic myocardial velocity; SBP, systolic blood pressure; SD, standard deviation; TM, thalassemia major.

PWS were different significantly $(p<0.001)$. Doppler tissue imaging findings, such as left $\mathrm{S}^{\prime}(p=0.012)$, left $\mathrm{E}^{\prime}(p<0.001)$, right $S^{\prime}(p<0.001)$, right $\mathrm{E}^{\prime}(p=0.018)$, LVMI $(p<0.001)$, left $\mathrm{E}$ ' $/ \mathrm{A}^{\prime}(p<0.001)$, and right $\mathrm{E}^{\prime} / \mathrm{A}^{\prime}(p=0.038)$ were different in patients compared with controls. Aortic stiffness parameters such as; ASI $(p<0.001)$, PP $(p<0.001)$, and PSEM $(p<0.001)$ were higher in patients, while AS $(p<0.002)$ and AD $(p<0.001)$ were significantly low. - Fig. 2 showed the boxplot presentation for four aortic stiffness.
- Table 3 showed the quantities variables comparative in TM and controls children based on parametric independent $t$-test. From the table resulted that the variables of Aos $(p=0.009)$. LVDD $(p<0.001)$, LVDS $(p<0.001)$, EF $(p<0.001)$ FS $(p<0.001)$, and BMI $(p<0.001)$ were different in patients when compared with controls.

- Table 4 showed the correlation between aortic stiffness parameters and other studied variables in patients. From the table observed that ASI was correlated with age $(p<0.001)$, 
Aortic Elasticity in Thalassemia Noori et al. e67

Table 2 Quantities variables comparative in TM and controls based on nonparametric Mann-Whitney U-test

\begin{tabular}{|c|c|c|c|c|c|c|c|}
\hline Variables & Groups & Mean & SD & $\begin{array}{l}\text { Mean } \\
\text { rank }\end{array}$ & $\begin{array}{l}\text { Sum of } \\
\text { ranks }\end{array}$ & MWU & $p$-Value \\
\hline \multirow[t]{2}{*}{ Age $(y)$} & TM patients & 13.98 & 3.84 & 68.19 & $4,432.50$ & \multirow[t]{2}{*}{$1,937.50$} & \multirow[t]{2}{*}{0.413} \\
\hline & Controls & 13.42 & 3.45 & 62.81 & $4,082.50$ & & \\
\hline \multirow[t]{2}{*}{ Weight $(\mathrm{kg})$} & TM patients & 36.23 & 11.71 & 51.79 & $3,366.50$ & \multirow[t]{2}{*}{$1,221.50$} & \multirow[t]{2}{*}{$<0.001$} \\
\hline & Controls & 46.75 & 13.96 & 79.21 & $5,148.50$ & & \\
\hline \multirow[t]{2}{*}{ Height $(\mathrm{cm})$} & TM patients & 139.98 & 16.54 & 54.27 & $3,527.50$ & \multirow[t]{2}{*}{$1,382.50$} & \multirow[t]{2}{*}{0.001} \\
\hline & Controls & 150.46 & 15.71 & 76.73 & $4,987.50$ & & \\
\hline \multirow[t]{2}{*}{$\mathrm{SBP}(\mathrm{mm} \mathrm{Hg})$} & TM patients & 103.46 & 5.99 & 57.08 & $3,710.00$ & \multirow[t]{2}{*}{$1,565.00$} & \multirow[t]{2}{*}{0.009} \\
\hline & Controls & 107.31 & 7.08 & 73.92 & $4,805.00$ & & \\
\hline \multirow[t]{2}{*}{$\mathrm{DBP}(\mathrm{mm} \mathrm{Hg})$} & TM patients & 63.52 & 5.34 & 40.81 & $2,652.50$ & \multirow[t]{2}{*}{507.50} & \multirow[t]{2}{*}{$<0.001$} \\
\hline & Controls & 72.62 & 5.24 & 90.19 & $5,862.50$ & & \\
\hline \multirow[t]{2}{*}{ IVSD (cm) } & TM patients & 0.86 & 0.17 & 88.35 & $5,743.00$ & \multirow[t]{2}{*}{627.00} & \multirow[t]{2}{*}{$<0.001$} \\
\hline & Controls & 0.65 & 0.11 & 42.65 & $2,772.00$ & & \\
\hline \multirow[t]{2}{*}{ PWD (cm) } & TM patients & 0.42 & 0.07 & 82.63 & $5,371.00$ & \multirow[t]{2}{*}{999.00} & \multirow[t]{2}{*}{$<0.001$} \\
\hline & Controls & 0.36 & 0.05 & 48.37 & $3,144.00$ & & \\
\hline \multirow[t]{2}{*}{ IVSS (cm) } & TM patients & 1.01 & 0.2 & 81.75 & $5,314.00$ & \multirow[t]{2}{*}{$1,056.00$} & \multirow[t]{2}{*}{$<0.001$} \\
\hline & Controls & 0.85 & 0.16 & 49.25 & $3,201.00$ & & \\
\hline PWS (cm) & TM patients & 0.42 & 0.07 & 82.4 & $5,356.00$ & $1,014.00$ & $<0.001$ \\
\hline & Controls & 0.36 & 0.05 & 48.6 & $3,159.00$ & & \\
\hline Left $\mathrm{S}^{\prime}(\mathrm{m} / \mathrm{s})$ & TM patients & 0.08 & 0.01 & 57.44 & $3,733.50$ & $1,588.50$ & 0.012 \\
\hline & Controls & 0.09 & 0.02 & 73.56 & $4,781.50$ & & \\
\hline Left E'(m/s) & TM patients & 0.17 & 0.03 & 79.1 & $5,141.50$ & $1,228.50$ & $<0.001$ \\
\hline & Controls & 0.15 & 0.02 & 51.9 & $3,373.50$ & & \\
\hline Left $A^{\prime}(\mathrm{m} / \mathrm{s})$ & TM patients & 0.06 & 0.02 & 60.16 & $3,910.50$ & $1,765.50$ & 0.099 \\
\hline & Controls & 0.07 & 0.02 & 70.84 & $4,604.50$ & & \\
\hline Right S' (m/s) & TM patients & 0.12 & 0.1 & 81.61 & $5,304.50$ & $1,065.50$ & $<0.001$ \\
\hline & Controls & 0.09 & 0.01 & 49.39 & $3,210.50$ & & \\
\hline Right E' (m/s) & TM patients & 0.15 & 0.03 & 57.8 & $3,757.00$ & $1,612.00$ & 0.018 \\
\hline & Controls & 0.16 & 0.02 & 73.2 & $4,758.00$ & & \\
\hline Right $A^{\prime}(\mathrm{m} / \mathrm{s})$ & TM patients & 0.08 & 0.02 & 65.51 & $4,258.00$ & $2,112.00$ & 0.998 \\
\hline & Controls & 0.08 & 0.01 & 65.49 & $4,257.00$ & & \\
\hline ASI & TM patients & 5.47 & 0.43 & 84.26 & $5,477.00$ & 893.00 & $<0.001$ \\
\hline & Controls & 5.09 & 0.22 & 46.74 & $3,038.00$ & & \\
\hline Strain (\%) & TM patients & 19.82 & 8.6 & 55.03 & $3,577.00$ & $1,432.00$ & 0.002 \\
\hline & Controls & 22.6 & 4.16 & 75.97 & $4,938.00$ & & \\
\hline $\mathrm{PP}(\mathrm{mm} / \mathrm{Hg})$ & TM patients & 39.94 & 5.36 & 81.61 & $5,304.50$ & $1,065.50$ & $<0.001$ \\
\hline & Controls & 34.69 & 5.79 & 49.39 & $3,210.50$ & & \\
\hline $\mathrm{AD}\left(\mathrm{cm}^{2} \times\right.$ dyne $\left.^{-1} \times 10^{-6}\right)$ & TM patients & 1.01 & 0.43 & 47.69 & $3,100.00$ & 955.00 & $<0.001$ \\
\hline & Controls & 1.35 & 0.39 & 83.31 & $5,415.00$ & & \\
\hline PSEM (kPa) & TM patients & 2.46 & 1.44 & 83.31 & $5,415.00$ & 955.00 & $<0.001$ \\
\hline & Controls & 1.59 & 0.43 & 47.69 & $3,100.00$ & & \\
\hline RWT & TM patients & 0.2 & 0.03 & 69.84 & $4,539.50$ & $1,830.50$ & 0.189 \\
\hline & Controls & 0.19 & 0.03 & 61.16 & $3,975.50$ & & \\
\hline
\end{tabular}


Table 2 (Continued)

\begin{tabular}{|l|l|l|l|l|l|l|l|}
\hline Variables & Groups & Mean & SD & $\begin{array}{l}\text { Mean } \\
\text { rank }\end{array}$ & $\begin{array}{l}\text { Sum of } \\
\text { ranks }\end{array}$ & MWU & $p$-Value \\
\hline \multirow{2}{*}{ LVMI $\left(\mathrm{g} / \mathrm{m}^{2}\right)$} & TM patients & 48.01 & 15.61 & 89.19 & $5,797.50$ & 572.50 & $<0.001$ \\
\cline { 2 - 7 } & Controls & 28.66 & 9.29 & 41.81 & $2,717.50$ & & \\
\hline \multirow{2}{*}{ Left $\mathrm{E}^{\prime} / \mathrm{A}^{\prime}$} & TM patients & 2.72 & 0.68 & 78.43 & $5,098.00$ & $1,272.00$ & $<0.001$ \\
\cline { 2 - 7 } & Controls & 2.27 & 0.63 & 52.57 & $3,417.00$ & & \\
\hline \multirow{2}{*}{ Right $\mathrm{E}^{\prime} / \mathrm{A}^{\prime}$} & TM patients & 1.93 & 0.47 & 58.65 & $3,812.00$ & $1,667.00$ & 0.038 \\
\cline { 2 - 6 } & Controls & 2.04 & 0.3 & 72.35 & $4,703.00$ & & \\
\hline
\end{tabular}

Abbreviations: A', late diastolic myocardial velocity; DBP, diastolic blood pressure; E', early diastolic myocardial relaxation velocity; IVSD, interventricular septal dimension in diastole; IVSS, interventricular septal dimension in systole; LVMI, left ventricular mass index; MWU, MannWhitney U test; PWD, posterior wall dimension in diastole; PWS, posterior wall dimension in systole; RWT, relative wall thickness; S', systolic myocardial velocity; SBP, systolic blood pressure; SD, standard deviation; TM, thalassemia major.

weight $(p<0.001)$, height $(p=0.001)$, Aod $(p=0.005)$, Aos $(p<0.001)$, IVSD $(p<0.001)$, LVDD $(p=0.008), \quad$ PWD $(p=0.010), \quad$ IVSS $\quad(p<0.001), \quad$ PWS $\quad(p=0.007), \quad$ BMI $(p=0.002)$, and LVMI $(p<0.001)$. Strain was correlated with Aod $(p<0.001)$ and Left E"/A' $(p=0.028)$ significantly. PP was correlated with SBP $(p<0.001)$ and DBP $(p=0.002)$ significantly. AD was correlated with $\operatorname{SBP}(p=0.039)$ and $\mathrm{AD}$ $(p<0.001)$ significantly. The PSEM was correlated only with Aod $(p=0.029)$.

The patients were grouped in different age groups, such as 17 years in age lower that 10 years, 19 years in age group of 10 to 15 years, and the remaining patients included in the last age group of 15 to 19 years. Therefore, - Table $\mathbf{5}$ showed aortic stiffness parameters comparison in age groups of TM patients, indicating that two indices of ASI and aortic strain were different in TM patients considering age. ASI was high $(5.84 \pm 0.51)$ in the age group of $\leq 10$ years and then increased by age so that reached to $(5.32 \pm 0.33)$ for the age group of $>15$ years $(\mathrm{F}=11.415, p<0.001)$. Aortic strain levels had the highest level (24.26) in the age group of 11 to 15 years and had the lowest level (17.76) in the age group of $>15$ years. The TM patients had no different levels of PP, aortic distensibility and pressure strain elastic modulus in different age groups. The difference of aortic stiffness index observed in paired age groups of ( $\leq 10$ and 11 to 15$)$ and $(\leq 10$ and $>15)$ years. For the Aorta strain the difference observed in paired age group of (11 to 15 and $>15$ ) years.

\section{Discussion}

Despite the fact that the futurity and personal atonement of TM patients have particularly expanded as of late, the patients still experience the ill effects of numerous difficulties. ${ }^{17}$ At present, the most widely recognized complexity and the primary driver of death in these patients are transfusion-related hemosiderosis-incited heart failure and fatal arrhythmia. ${ }^{18}$ In these patients, iron deposition in the heart does not occur until the other organs are saturated and iron overload may result in systolic and diastolic dysfunction of the LV accumulation and of hepatic iron does not represent the deposition of the myocardial iron. ${ }^{19}$ An improvement in parameters of aortic stiffness in the absence of cardiac iron overload in patients with TM has been demonstrated. ${ }^{13}$ Aortic stiffness increases SBP and LVM due to decreased buffering mechanism and rapid return of reflective pressure waves from periphery. Associated decrease in diastolic pressure predisposes to increased cardiovascular disorder by reducing coronary blood flow. ${ }^{20}$ In the present study, the patients had lower SBP and DBP compared with controls and some of conventional and Doppler tissue findings were different. In the patients, aortic stiffness index, PP, and pressure strain elastic modulus were higher, while aortic strain and aortic distensibility were lower compared with controls. Aortic stiffness index was correlated with diastole and systole aorta and LVMI. Aorta train was correlated with diastole aorta and Left E'/A'. PP was correlated with SBP and DBP. Aortic distensibility was correlated with SBP and diastole aorta. The pressure strain elastic modulus was correlated with only diastole aorta. Noori et al ${ }^{15,21,22}$ found that left EF and FS were decreased in TM patients compared with healthy ones that was consistent with the present study. In some studies, LVMI found with an increased in TM patients compared with controls same our findings. ${ }^{16,22}$ Noori et al ${ }^{16,21}$ found that LVDD was lower in control when found higher in another study. ${ }^{15}$ In our late study, we concluded that LVSD, PWD, FS, EF, right $S^{\prime}$, right $A^{\prime}$, and LVMI were different between TM patients and healthy children. ${ }^{16}$ In another study, Noori et $\mathrm{al}^{23}$ found Doppler tissue parameters such as left $S^{\prime}$, left $A^{\prime}$, and right $A^{\prime}$ were higher in controls compared with TM patients. When the parameters of left $E$ ', right $S^{\prime}$, and right $\mathrm{E}^{\prime}$ were similar, comparable with the related findings of the present study. Similar to the patients of our study, Sahin et $\mathrm{al}^{9}$ conducted a study on asymptomatic TM patients to determine the changes of aortic stiffness indices. They found higher SBP and DBP and lower PP in controls compared with TM patients. Regarding the stiffness indices, aortic strain, and aortic distensibility were lower and aortic stiffness index and elastic modulus were higher in TM patients. They also found that DBP was correlated with only aortic stiffness. Gedikli et al $^{12}$ found smaller body size, lower SBP and DBP, and higher Aos and Aod in TM patients compared with controls. Aortic strain, distensibility, and stiffness index values also were higher in TM patients. In their study, aortic strain had a significant correlation with 


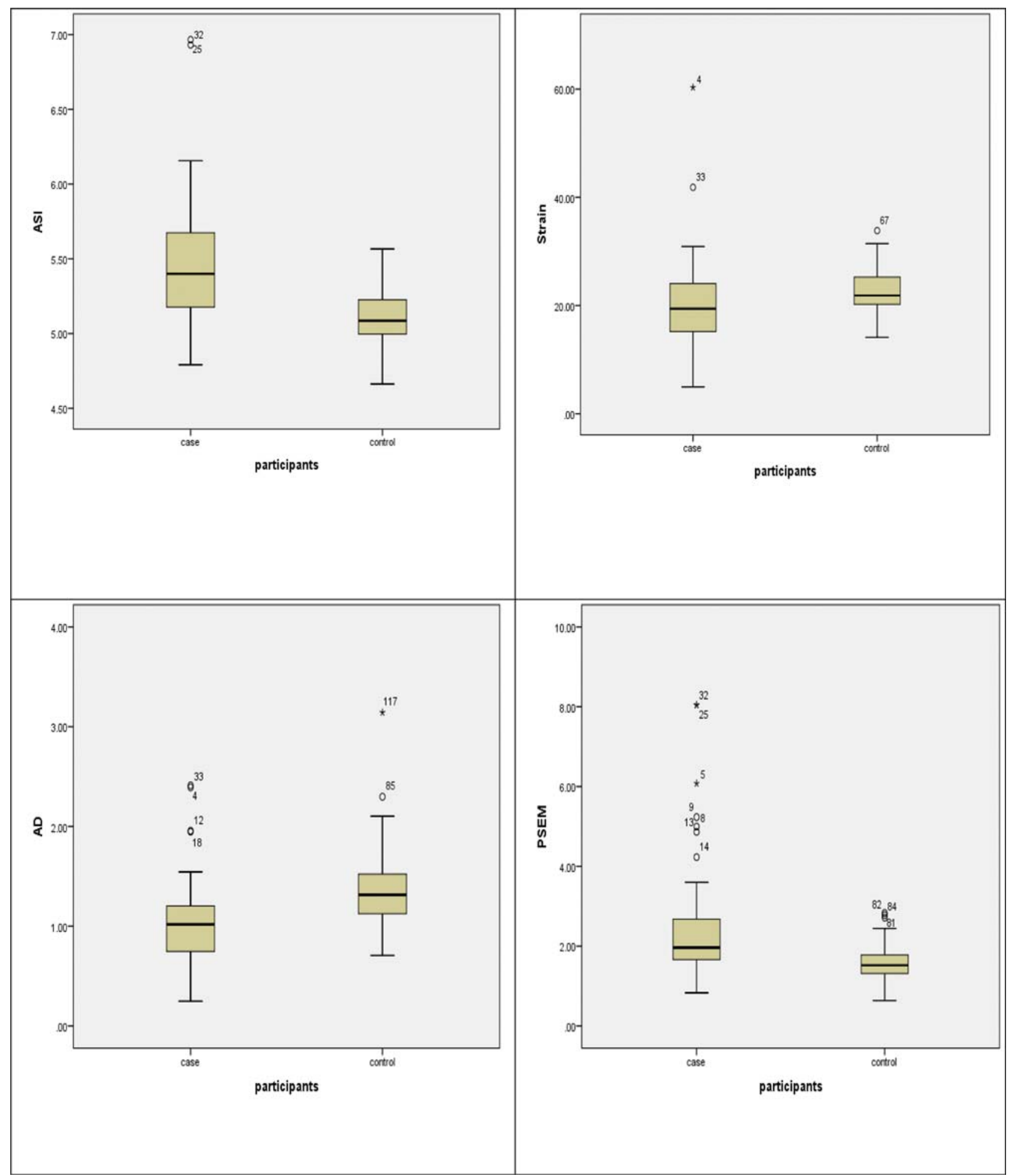

Fig. 2 Boxplot presentation for aortic stiffness parameters for thalassemia and controls. ASI, aortic stiffness index; PSEM, pressure strain elastic modulus.

age and body surface area (BSA), aortic distensibility was correlated with age, SBP. Tantawy et $\mathrm{l}^{24}$ led a study on $60 \mathrm{TM}$ patients. They resulted that aortic strain, aortic distensibility, aortic stiffness index, and elastic modulus were different in patients compared with controls. In their study, patients had significantly lower weight and height than controls. LVMIs, aortic stiffness index were higher in TM children. Whereas aortic strain, aortic distensibility, EF, and FS were lower. In addition, aortic stiffness was positively correlated to aortic distensibility. Cusmà Piccione et $\mathrm{al}^{11}$ conducted a study to evaluate LV myocardial deformation and carotid arterial stiffness in patients with asymptomatic TM without significant myocardial iron overload. Their patients who were adult, went under ultrasonography using a color Doppler echocardiography with high resolution. The stiffness parameters were obtained from the right and left common carotid 
Table 3 Quantities variables comparative in TM and controls based on parametric Independent $t$-test

\begin{tabular}{|c|c|c|c|c|c|}
\hline Variables & Groups & Mean & SD & $T$ & $p$-Value \\
\hline \multirow[t]{2}{*}{ Aod $(\mathrm{cm})$} & TM patients & 1.97 & 0.3 & \multirow[t]{2}{*}{-1.280} & \multirow[t]{2}{*}{0.203} \\
\hline & Controls & 2.04 & 0.26 & & \\
\hline \multirow[t]{2}{*}{ Aos $(\mathrm{cm})$} & TM patients & 2.35 & 0.31 & \multirow[t]{2}{*}{-2.665} & \multirow[t]{2}{*}{0.009} \\
\hline & Controls & 2.49 & 0.27 & & \\
\hline \multirow[t]{2}{*}{ LVDD (cm) } & TM patients & 4.26 & 0.44 & \multirow[t]{2}{*}{6.47} & \multirow[t]{2}{*}{$<0.001$} \\
\hline & Controls & 3.76 & 0.44 & & \\
\hline \multirow[t]{2}{*}{ LVDS (cm) } & TM patients & 2.42 & 0.36 & \multirow[t]{2}{*}{6.72} & \multirow[t]{2}{*}{$<0.001$} \\
\hline & Controls & 2.04 & 0.29 & & \\
\hline \multirow[t]{2}{*}{$\mathrm{EF}(\%)$} & TM patients & 0.74 & 0.06 & \multirow[t]{2}{*}{-3.68} & \multirow[t]{2}{*}{$<0.001$} \\
\hline & Controls & 0.77 & 0.05 & & \\
\hline \multirow[t]{2}{*}{ FS (\%) } & TM patients & 0.41 & 0.05 & \multirow[t]{2}{*}{-5.68} & \multirow[t]{2}{*}{$<0.001$} \\
\hline & Controls & 0.46 & 0.05 & & \\
\hline \multirow[t]{2}{*}{ BMI $\left(\mathrm{kg} / \mathrm{m}^{2}\right)$} & TM patients & 17.93 & 2.66 & \multirow[t]{2}{*}{-4.80} & \multirow[t]{2}{*}{$<0.001$} \\
\hline & Controls & 20.11 & 2.52 & & \\
\hline
\end{tabular}

Abbreviations: Aod, aortic diameter in diastole; Aos, aortic diameter in systole; BMI, body mass index; EF, ejection fraction; FS, fractional shortening; LVDD, left ventricular end diastolic dimension; LVDS, left ventricular end systolic dimension; SD, standard deviation; T, Student's t-test value; TM, thalassemia major.

Table 4 Association of study variables with Stiffness indices in TM patients

\begin{tabular}{|c|c|c|c|c|c|c|c|c|c|c|c|c|}
\hline Variables & Statistics & ASI & Strain & PP & $A D$ & PSEM & Variables & ASI & Strain & PP & $A D$ & PSEM \\
\hline \multirow{2}{*}{$\begin{array}{l}\text { Age } \\
\text { (y) }\end{array}$} & $r$ & -0.465 & -0.164 & 0.051 & -0.134 & -0.013 & \multirow[t]{2}{*}{$\mathrm{EF}(\%)$} & 0.009 & 0.198 & 0.046 & 0.201 & -0.051 \\
\hline & $p$ & $<0.001$ & 0.193 & 0.687 & 0.287 & 0.918 & & 0.941 & 0.114 & 0.715 & 0.109 & 0.687 \\
\hline \multirow{2}{*}{$\begin{array}{l}\text { Weight } \\
(\mathrm{kg})\end{array}$} & $r$ & -0.448 & -0.186 & 0.028 & -0.156 & 0.014 & \multirow[t]{2}{*}{ FS (\%) } & 0.094 & 0.067 & 0.051 & 0.079 & 0.119 \\
\hline & $p$ & $<0.001$ & 0.137 & 0.827 & 0.214 & 0.91 & & 0.458 & 0.596 & 0.684 & 0.532 & 0.347 \\
\hline \multirow{2}{*}{$\begin{array}{l}\text { Height } \\
\text { (cm) }\end{array}$} & $r$ & -0.414 & -0.239 & 0.073 & -0.226 & 0.049 & \multirow{2}{*}{$\begin{array}{l}\text { Left } S^{\prime} \\
(\mathrm{m} / \mathrm{s})\end{array}$} & -0.114 & 0.053 & -0.15 & 0.149 & -0.041 \\
\hline & $p$ & 0.001 & 0.055 & 0.563 & 0.071 & 0.701 & & 0.365 & 0.674 & 0.233 & 0.236 & 0.743 \\
\hline \multirow{2}{*}{$\begin{array}{l}\text { IVSD } \\
(\mathrm{cm})\end{array}$} & $r$ & -0.476 & 0.095 & 0.05 & 0.124 & -0.102 & \multirow{2}{*}{$\begin{array}{l}\text { Left E' } \\
(\mathrm{m} / \mathrm{s})\end{array}$} & -0.126 & 0.105 & 0.007 & 0.091 & -0.104 \\
\hline & $p$ & $<0.001$ & 0.453 & 0.695 & 0.326 & 0.419 & & 0.316 & 0.406 & 0.956 & 0.47 & 0.409 \\
\hline \multirow{2}{*}{$\begin{array}{l}\text { LVDD } \\
(\mathrm{cm})\end{array}$} & $r$ & -0.325 & 0.031 & 0.215 & -0.074 & -0.013 & \multirow{2}{*}{$\begin{array}{l}\text { Left A' } \\
(\mathrm{m} / \mathrm{s})\end{array}$} & -0.13 & -0.147 & -0.067 & -0.103 & 0.049 \\
\hline & $p$ & 0.008 & 0.805 & 0.086 & 0.559 & 0.92 & & 0.303 & 0.244 & 0.597 & 0.416 & 0.699 \\
\hline \multirow{2}{*}{$\begin{array}{l}\text { PWD } \\
(\mathrm{cm})\end{array}$} & $r$ & -0.317 & -0.075 & 0.029 & -0.044 & 0.042 & \multirow{2}{*}{$\begin{array}{l}\text { Right } \mathrm{S}^{\prime} \\
(\mathrm{m} / \mathrm{s})\end{array}$} & -0.038 & -0.017 & 0.019 & -0.024 & 0.009 \\
\hline & $p$ & 0.01 & 0.554 & 0.817 & 0.729 & 0.737 & & 0.762 & 0.896 & 0.883 & 0.853 & 0.946 \\
\hline \multirow{2}{*}{$\begin{array}{l}\text { IVSS } \\
(\mathrm{cm})\end{array}$} & $r$ & -0.461 & -0.031 & 0.023 & 0.015 & -0.008 & \multirow{2}{*}{$\begin{array}{l}\text { Right } E^{\prime} \\
(\mathrm{m} / \mathrm{s})\end{array}$} & -0.088 & 0.025 & -0.038 & 0.075 & 0.034 \\
\hline & $p$ & $<0.001$ & 0.804 & 0.856 & 0.906 & 0.947 & & 0.486 & 0.846 & 0.766 & 0.552 & 0.789 \\
\hline \multirow{2}{*}{$\begin{array}{l}\text { LVDS } \\
(\mathrm{cm})\end{array}$} & $r$ & -0.194 & -0.128 & 0.095 & -0.189 & 0.045 & \multirow{2}{*}{$\begin{array}{l}\text { Right } A^{\prime} \\
(\mathrm{m} / \mathrm{s})\end{array}$} & -0.102 & -0.009 & -0.071 & 0.044 & 0.158 \\
\hline & $p$ & 0.121 & 0.311 & 0.452 & 0.132 & 0.723 & & 0.418 & 0.945 & 0.572 & 0.73 & 0.209 \\
\hline \multirow{2}{*}{$\begin{array}{l}\text { PWS } \\
(\mathrm{cm})\end{array}$} & $r$ & -0.33 & -0.069 & 0.039 & -0.042 & 0.038 & \multirow{2}{*}{$\begin{array}{l}\mathrm{BMI} \\
\left(\mathrm{kg} / \mathrm{m}^{2}\right)\end{array}$} & -0.377 & -0.027 & -0.001 & 0.006 & -0.02 \\
\hline & $p$ & 0.007 & 0.584 & 0.757 & 0.74 & 0.765 & & 0.002 & 0.831 & 0.992 & 0.96 & 0.875 \\
\hline \multirow{2}{*}{$\begin{array}{l}\text { Left } \\
E^{\prime} / A^{\prime}\end{array}$} & $r$ & 0.019 & 0.273 & 0.068 & 0.214 & -0.192 & \multirow{2}{*}{$\begin{array}{l}\text { LVMI } \\
\left(\mathrm{g} / \mathrm{m}^{2}\right)\end{array}$} & -0.458 & 0.044 & 0.111 & 0.019 & -0.073 \\
\hline & $p$ & 0.883 & 0.028 & 0.588 & 0.086 & 0.125 & & $<0.001$ & 0.725 & 0.379 & 0.883 & 0.565 \\
\hline \multirow{2}{*}{$\begin{array}{l}\text { Right } \\
E^{\prime} / A^{\prime}\end{array}$} & $r$ & 0.09 & 0.004 & 0.024 & -0.007 & -0.102 & \multirow[t]{2}{*}{ RWT } & -0.146 & -0.119 & -0.118 & -0.003 & 0.069 \\
\hline & $p$ & 0.476 & 0.975 & 0.851 & 0.954 & 0.421 & & 0.245 & 0.347 & 0.351 & 0.979 & 0.586 \\
\hline
\end{tabular}

Abbreviations: A', late diastolic myocardial velocity; AD, aortic destensibility; ASI, aortic stiffness index; BMI, body mass index; $E^{\prime}$, early diastolic myocardial relaxation velocity; EF, ejection fraction; FS, fractional shortening; IVSD, interventricular septal dimension in diastole; IVSS,

interventricular septal dimension in systole; LVDD, left ventricular end diastolic dimension; LVDS, left ventricular end systolic dimension; LVMI, left ventricular mass index; PP, pulse pressure; PSEM, pressure strain elastic modulus; PWD, posterior wall dimension in diastole; PWS, posterior wall dimension in systole; RWT, relative wall thickness; $S^{\prime}$, systolic myocardial velocity; TM, thalassemia major. 
Table 5 Aortic stiffness parameters comparison in age groups of TM patients

\begin{tabular}{|c|c|c|c|c|c|c|}
\hline $\begin{array}{l}\text { Aortic stiffness } \\
\text { parameters }\end{array}$ & Age groups (y) & Number & Mean & SD & F-Value & $p$-Value \\
\hline \multirow[t]{4}{*}{ ASI } & $\leq 10$ & 17 & 5.840 & 0.508 & \multirow[t]{4}{*}{11.415} & $<0.001$ \\
\hline & $11-15$ & 19 & 5.364 & 0.305 & & \\
\hline & $>15$ & 29 & 5.318 & 0.326 & & \\
\hline & Total & 65 & 5.469 & 0.433 & & \\
\hline \multirow[t]{4}{*}{ Strain (\%) } & $\leq 10$ & 17 & 18.355 & 7.341 & \multirow[t]{4}{*}{3.946} & 0.024 \\
\hline & $11-15$ & 19 & 24.262 & 11.722 & & \\
\hline & $>15$ & 29 & 17.762 & 5.544 & & \\
\hline & Total & 65 & 19.817 & 8.597 & & \\
\hline \multirow[t]{4}{*}{$\mathrm{PP}(\mathrm{mm} \mathrm{Hg})$} & $\leq 10$ & 17 & 37.941 & 4.351 & \multirow[t]{4}{*}{1.899} & 0.158 \\
\hline & $11-15$ & 19 & 41.316 & 4.956 & & \\
\hline & $>15$ & 29 & 40.207 & 5.930 & & \\
\hline & Total & 65 & 39.938 & 5.356 & & \\
\hline \multirow[t]{4}{*}{$\mathrm{AD}\left(\mathrm{cm}^{2} \times\right.$ dyne $\left.^{-1} \times 10^{-6}\right)$} & $\leq 10$ & 17 & 0.976 & 0.376 & \multirow[t]{4}{*}{1.974} & 0.148 \\
\hline & $11-15$ & 19 & 1.163 & 0.508 & & \\
\hline & $>15$ & 29 & 0.920 & 0.381 & & \\
\hline & Total & 65 & 1.006 & 0.427 & & \\
\hline \multirow[t]{4}{*}{ PSEM (kPa) } & $\leq 10$ & 17 & 2.785 & 2.182 & \multirow[t]{4}{*}{1.379} & 0.26 \\
\hline & $11-15$ & 19 & 2.026 & 0.920 & & \\
\hline & $>15$ & 29 & 2.553 & 1.118 & & \\
\hline & Total & 65 & 2.460 & 1.436 & & \\
\hline
\end{tabular}

Abbreviations: AD, aortic destensibility; ASI, aortic stiffness index; PP, pulse pressure; PSEM, pressure strain elastic modulus; SD, standard deviation; TM, thalassemia major.

arteries approximately $1 \mathrm{~cm}$ proximal to the bulb region. They found no differences between the patients and healthy population regarding the $\mathrm{LV}$ volume, EF, myocardial mass, diastolic indices, and all the echocardiography findings but observed higher elastic modulus and stiffness index in patients.

A strong link between arterial stiffness and age approved in both healthy and diseased populations such that aortic stiffness decreases sharply with age in the first decade of life, reaching a minimum at 10 years of age, and thereafter increasing with age in both genders. ${ }^{25}$ The underlying basis for these age-dependent changes is still incompletely understood. Pathologically, fracture and fragmentation of the elastin fibers after repetitive stress cycles with consequent dilation and stiffening have been observed. ${ }^{26}$

Central arteries stiffen progressively with age, whereas stiffness of muscular arteries changes little with age. ${ }^{25} \mathrm{Al}-$ though large artery stiffness increases with age independently of the presence of cardiovascular risk factors or other associated conditions, the extent of this increase may depend on several environmental or genetic factors. ${ }^{27}$ The impact of age on parameters of arterial stiffness among TM patients has been poorly studied. But Cho et al ${ }^{28}$ has conducted a study to find the effects of age on arterial stiffness in adulthood patients with newly diagnosed untreated hypertension. They found that age was well-known major determinants of arterial stiffness. They found augmentation index or augmentation pressure was significantly higher in the old hypertension group.

In similar, we did analysis to find the correlation between age and aortic stiffness indices in our TM patients. We found that aortic stiffness indices increases with age. Therefore, large artery stiffening can be considered as a marker of arterial age and should be considered as a major risk factor for cardiovascular events. The results of the present study suggested that parameters of arterial stiffness were more significantly affected by age rather than the level of BP.

TM is frequently associated with progressive LV systolic and diastolic dysfunction, leading to congestive heart failure. Aortic elastic properties are important determinants of left ventricular systolic and diastolic function. Clinical studies have also linked increased aortic stiffness to overt diastolic heart failure. ${ }^{12}$ By virtue of its elastic properties, the aorta influences LV diastolic function and whereby coronary blood flow. Impaired function of aorta may contribute to LV dysfunction in patients with TM. Also deteriorated aortic function may be associated with increased risk of coronary events. Because of extremely low level of lipid levels, thromboembolic events are rare in patients with TM. ${ }^{29}$ Taking into account low rate of atherogenic events, elastic properties of aorta should be thought of as a risk factor leading to left ventricular dysfunction in patients with TM. However, longterm followed studies considering relation between 
aortic elastic properties and cardiovascular morbidity are needed. ${ }^{12}$ From the study and literatures, provided that the first evidence that function of the arterial system in patients with TM is putting at risk by endothelial dysfunction and increased stiffness that may result in reduction of mechanical efficiency of the heart.

\section{Study Limitation}

One limitation was the use of brachial artery measurements for blood pressure values obtained to evaluate aortic elasticity, although the fact that blood pressure values obtained by using same technique in both TM and control groups did not affect the results and did not change the results. In addition, the study was a single-center study that was a reason for small number of patients.

\section{Conclusion}

From the study we concluded that aortic stiffness index, PP, and pressure strain elastic modulus were higher in TM patients when, aortic strain, aortic distensibility were lower. In TM patients, aortic stiffness index was correlated with LVMI. Strain was correlated with aorta in diastole. PP was correlated with SBP and DBP. Aortic distensibility was correlated with SBP and aorta in diastole. The pressure strain elastic modulus was correlated with aorta in diastole. Therefore, assessment of aortic elastic properties as nontraditional cardiovascular risk factors may contribute to the identification of cardiovascular risks in patients with thalassemia.

\section{Authors' Contributions}

N.M.M. contributed in conception, supervision, data collection, literature review, and critical review. A.T. participated in analysis and interpretation, writing manuscript, literature review, and critical review.

\section{Conflict of Interest}

None declared.

\section{Acknowledgments}

The authors would like to thank all the patients and their parents for warm and tolerate participation.

\section{References}

1 Sethi S, Rivera O, Oliveros R, Chilton R. Aortic stiffness: pathophysiology, clinical implications, and approach to treatment. Integr Blood Press Control 2014;7:29-34

2 Mozos I, Malainer C, Horbańczuk J, et al. Inflammatory markers for arterial stiffness in cardiovascular diseases. Frontiers in immunology. 2017 Aug 31;8:1058Cecelja M, Chowienczyk P. Arterial stiffening: causes and consequences. Artery Res 2013; 7:22-27

3 Ljungberg J, Johansson B, Engström KG, et al. Traditional cardiovascular risk factors and their relation to future surgery for valvular heart disease or ascending aortic disease: a case-referent study. J Am Heart Assoc 2017;6(05):e005133

4 Bayar N, Çekin AH, Arslan Ş, et al. Assessment of aortic elasticity in patients with celiac disease. Korean Circ J 2016;46(02):239-245
5 Ülger Z, Gülen F, Özyürek AR. Abdominal aortic stiffness as a marker of atherosclerosis in childhood-onset asthma: a casecontrol study. Cardiovasc J Afr 2015;26(01):8-12

6 Bektaş O, Günaydin ZY, Karagöz A, Akgedik R, Bayramoğlu A, Kaya A. The effects of treatment in patients with childhood asthma on the elastic properties of the aorta. Cardiovasc J Afr 2017;28(03): 165-169

7 Prenner SB, Chirinos JA. Arterial stiffness in diabetes mellitus. Atherosclerosis 2015;238(02):370-379

8 Zapolski T, Furmaga J, Jaroszyński A, Wysocka A, Rudzki S, Wysokiński AP. The reverse remodeling of the aorta in patients after renal transplantation - the value of aortic stiffness index: prospective echocardiographic study. BMC Nephrol 2017;18(01): 33

9 Sahin C, Basaran O, Altun I, et al. Assessment of myocardial performance index and aortic elasticity in patients with betaBTMmajor. J Clin Med Res 2015;7(10):795-801

10 Sherief LM, Dawood O, Ali A, et al. Premature atherosclerosis in children with beta-thalassemia major: New diagnostic marker. BMC Pediatr 2017;17(01):69

11 Cusmà Piccione $M$, Piraino $B$, Zito $C$, et al. Early identification of cardiovascular involvement in patients with $\beta$-thalassemia major. Am J Cardiol 2013;112(08):1246-1251

12 Gedikli O, Altinbas A, Orucoglu A, et al. Elastic properties of the ascending aorta in patients with $\beta$-thalassemia major. Echocardiography 2007;24(08):830-836

13 Stakos DA, Margaritis D, Tziakas DN, et al. Cardiovascular involvement in patients with $\beta$-thalassemia major without cardiac iron overload. Int J Cardiol 2009;134(02):207-211

14 Cheung YF, Chan GC, Ha SY. Arterial stiffness and endothelial function in patients with beta-thalassemia major. Circulation 2002;106(20):2561-2566

15 Noori N, Mohamadi M, Keshavarz K, Alavi SM, Mahjoubifard M, Mirmesdagh Y. Comparison of right and left side heart functions in patients with thalassemia major, patients, patients with thalassemia intermedia, and control group. J Tehran Univ Heart Cent 2013;8(01):35-41

16 Noori NM, Teimouri A, Nakhaee Moghadam M, Bagheri H. Tumor necrosis factor alpha, n-terminal pro brain natriuretic peptide and interleukin-6 correlations with Doppler tissue imaging findings in major BTM patients. Int J Pediatr 2019;7(10): 10255-10268

17 Succar J, Musallam KM, Taher AT. Thalassemia and venous thromboembolism. Mediterr J Hematol Infect Dis 2011;3;. Doi: 10.4084/MJHID.2011.025

18 Yaman A, Pamir IS, Yarali N, et al. Common complications in betaBTMpatients. Int J Hematol Oncol 2013;28(04):193-199

19 Kremastinos DT, Tsetsos GA, Tsiapras DP, Karavolias GK, Ladis VA, Kattamis CA. Heart failure in beta thalassemia: a 5-year follow-up study. Am J Med 2001;111(05):349-354

20 Cavalcante JL, Lima JA, Redheuil A, Al-Mallah MH. Aortic stiffness: current understanding and future directions. J Am Coll Cardiol 2011;57(14):1511-1522

21 Noori NM, Teimouri A, Anvari N. Diagnostic value of $n$ terminal pro B type natriuretic peptide (NT-pro BNP) in cardiac involvement in patients with beta thalassemia. Int J Pediatr 2017;5(04): 4641-4662

22 Noori NM, Keshavarz K, Shahriar M. Cardiac and pulmonary dysfunction in asymptomatic beta-thalassanemia major. Asian Cardiovasc Thorac Ann 2012;20(05):555-559

23 Noori NM, Teimouri A, Nakhaey Moghaddam M. Diagnostic value of NT-pro BNP biomarker and echocardiography in cardiac involvements in beta- $\beta$ TMpatients. Int J Pediatr 2017;5(11): 6077-6094

24 Tantawy AA, Adly AA, El Maaty MG, Amin SA. Subclinical atherosclerosis in young beta-thalassemia major patients. Hemoglobin 2009;33(06):463-474 
25 Kohn JC, Lampi MC, Reinhart-King CA. Age-related vascular stiffening: causes and consequences. Front Genet 2015;6:112

26 Cecelja M, Chowienczyk P. Role of arterial stiffness in cardiovascular disease. JRSM Cardiovasc Dis 2012;1(04):1-0

27 Cecelja M, Chowienczyk P. Dissociation of aortic pulse wave velocity with risk factors for cardiovascular disease other than hypertension: a systematic review. Hypertension 2009;54(06): $1328-1336$
28 Cho SK, Cho SK, Kim KH, et al. Effects of age on arterial stiffness and blood pressure variables in patients with newly diagnosed untreated hypertension. Korean Circ J 2015;45(01):44-50

29 Gullu H, Erdogan D, Caliskan M, et al. Interrelationship between noninvasive predictors of atherosclerosis: transthoracic coronary flow reserve, flow-mediated dilation, carotid intima-media thickness, aortic stiffness, aortic distensibility, elastic modulus, and brachial artery diameter. Echocardiography 2006;23(10):835-842 